\title{
Striae distensae over scalp: A trichoscopic revelation
}

\section{Subrata Malakar, Priya Diwaker}

Department of Dermatology, Rita Skin Foundation, Kolkata, India

Corresponding author: Dr. Priya Diwaker, E-mail: priyadiwaker@gmail.com

Sir,

Striae distensae is a common disfiguring cutaneous condition which is characterized by linear, smooth and atrophic bands over the skin. It is a reflection of breaks in the connective tissue and occurs at the areas of dermal damage. The formation of striae distensae has been attributed to underlying mast cell degranulation with subsequent damage of elastin and collagen [1].

On one hand, striae can be the end result of various physiological conditions like pregnancy, adrenocortical excess and change in the body habitus, while on the other hand they are indicators of excessive topical steroid use $[2,3]$.

Topical corticosteroid is considered as the first line therapy in treating conditions like alopecia areata and psoriasis. While its appropriate and accurate use can provide satisfactory results, its over-usage can lead to inadvertent effects such as development of erythema, telangiectasia, acneiform eruptions, striae and eventually atrophy and scarring. The misuse of steroid on the face can be picked up easily by the signs mentioned afore. However on the scalp, due to the presence of hair, these signs can easily be missed. The role of trichoscopy holds importance especially in treating scalp lesions as these signs can be identified much before they are appreciated clinically.

We herein report 3 cases of striae distensae over the scalp detected incidentally while examining the scalp of patients on topical steroids.

A 35-year old female presented with patchy hair loss and was applying topical beclomethasone prescribed by her previous Dermatologist. On trichoscopy, there was presence of exclamation mark hair and yellow dots confirming the diagnosis of alopecia areata. Trichoscopy also demonstrated linear, atrophic bands on her scalp; striae distensae along with telangiectasia (Fig. 1). On taking a detailed history, the patient confessed to applying topical steroid for a long duration.

Keeping this trichoscopic finding in mind we subsequently started looking for similar linear atrophic bands on scalp of patients who were treated with topical steroids.

A 17-year old male having patchy hair loss for 6 months who was applying a lotion, bought over the counter, reported to us. He complained of itching at the site of application of the lotion. Trichoscopic evaluation confirmed him to be a case of alopecia areata (Fig. 2). He also had features of steroid misuse like telangiectasia and linear white atrophic bands suggestive of striae distensae. The lotion was later on identified to be fluocinolone acetonide $0.01 \%$.

A 28-year old female presented with hair loss for two years. She had observed widening of her central parting and thinning of her pony tail. She visited a general practitioner who prescribed beclomethasone lotion, which she had been using for the past one year with no significant improvement. After taking detailed history to rule out chronic telogen effluvium, we proceeded for trichoscopy and observed hair diameter variability and multiple vellus hair at the frontal region which confirmed the diagnosis of female pattern hair loss. Trichoscopy also demonstrated the presence of telangiectasia with few, linear, white streaks which were arranged in parallel to form a band indicating striae distensae.

We would like to highlight that a tool as simple as a dermoscope can help us identify the steroid overuse. Periodic monitoring of the patient on topical corticosteroids can reveal subtle changes of dermal

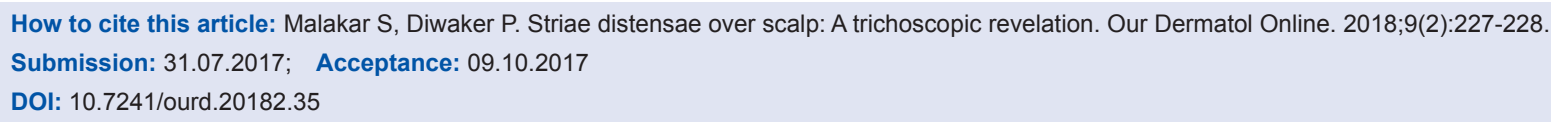




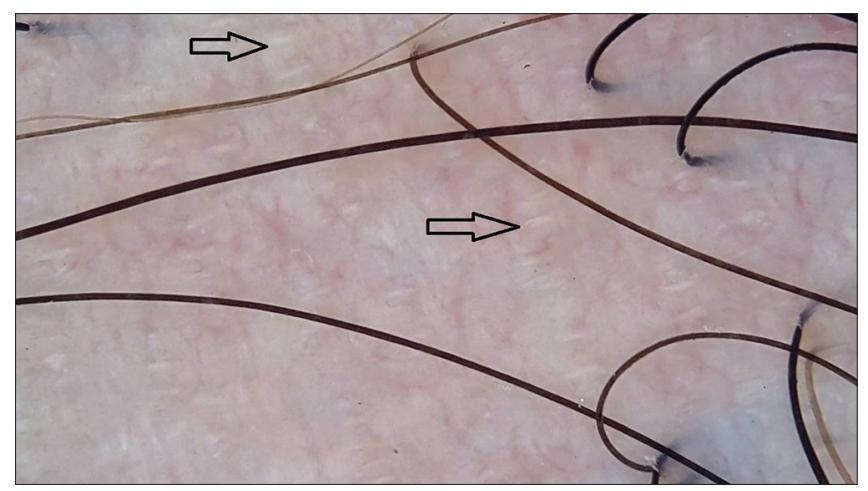

Figure 1: Linear atrophic bands (straie distensae) and telangiectasia over scalp on a patient with alopecia areata.

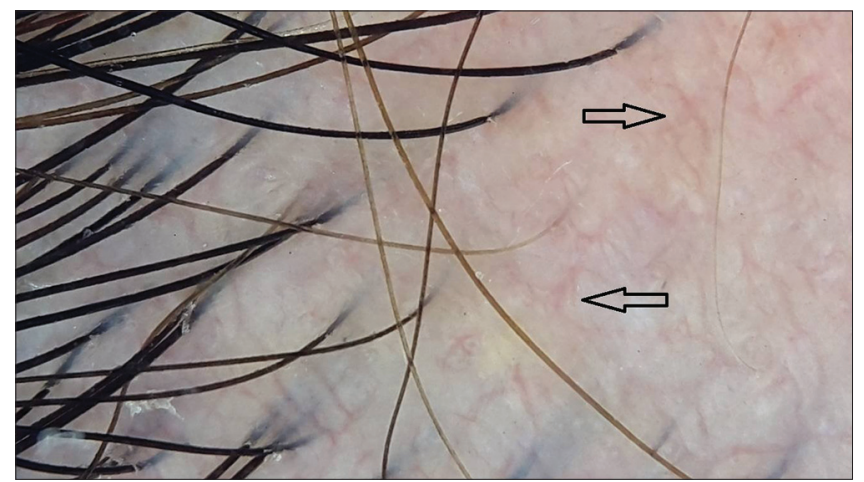

Figure 2: Telangiectasia over the scalp seen after steroid misuse. damage. There might be a need to revise the treatment options in such cases and switch them to non-steroidal medications. An observant physician with minimal effort and time can easily recognize complications of steroid misuse like scarring and telangiectasia in patients and correct the damage done. Thus, trichoscopy is not only a diagnostic tool but also a monitoring tool wherein it can reveal the tell-tale signs of inadvertent topical therapy.

\section{REFERENCES}

1. Sheu HM, Yu HS, Chang CH. Mast cell degranulation and elastolysis in the early stage of striae distensae. J Cutan Pathol. 1991;18:410-6.

2. Awley TJ, Yancey KB. Skin changes and diseases in pregnancy.In: Freedberg IM, Eisen AZ, Wolff K, Austen KF, Goldsmith LA, Katz SI, editors. Fitzpatrick's Dermatology in generalmedicine. $6^{\text {th }}$ edn. New York: McGraw-Hill; 2003. p. 1362.

3. Burrows NP, Lovell CR. Disorders of connective tissue. In: BurnsT, Breathnach S, Cox N, Griffith C, editors. Rook's Textbook of dermatology, $7^{\text {th }}$ edn. Oxford: Blackwell Science; 2004. p. 46-7.

Copyright by Subrata Malakar, et al. This is an open-access article distributed under the terms of the Creative Commons Attribution License, which permits unrestricted use, distribution, and reproduction in any medium, provided the original author and source are credited. Source of Support: Nil, Conflict of Interest: None declared. 